\title{
Production and characterization of titanium carbide particulate reinforced AA6061 aluminum alloy composites using stir casting
}

\author{
J. J. Moses ${ }^{1}$, I. Dinaharan ${ }^{2}$, S. J. Sekhar ${ }^{1 *}$ \\ ${ }^{1}$ Department of Mechanical Engineering, St. Xavier's Catholic College of Engineering, \\ Nagercoil 629003, Tamil Nadu, India \\ ${ }^{2}$ Department of Mechanical Engineering Science, University of Johannesburg, Auckland Park Kingsway Campus, \\ Johannesburg 2006, South Africa
}

Received 7 April 2014, received in revised form 3 February 2015, accepted 3 February 2015

\begin{abstract}
Stir casting is an economical method to produce aluminum matrix composites. In the present work, composites of aluminum alloy AA6061 reinforced with various amounts $(0,5$, 10 and 15 wt.\%) of $\mathrm{TiC}$ particles were prepared by stir casting technique. X-ray diffraction patterns of the prepared composites clearly revealed the incorporation of $\mathrm{TiC}$ particles without the presence of any other compounds. The microstructures of the composites were studied using optical and scanning electron microscopy. It was observed that the TiC particles distributed all over the composite and properly bonded to the matrix alloy. Local clusters of $\mathrm{TiC}$ particles were also seen in a few places. The result shows that the reinforcement of $\mathrm{TiC}$ particles enhances the microhardness, ultimate tensile strength and wear resistance of the composite. The details of fracture morphology, worn surface, and wear debris are also presented in this paper.
\end{abstract}

K e y words: metal matrix composites, stir casting, microstructure, mechanical properties

\section{Introduction}

The concept of reinforcing aluminum alloys with ceramic particles gave birth to a new class of material known as aluminum matrix composites (AMCs) a few decades ago. AMCs grabbed the attention of aircraft, automotive and other industries owing to their superior properties such as high specific strength, high elastic modulus, excellent friction and wear resistance, low thermal expansion coefficients, etc. [1-3]. AMCs are favored over conventional aluminum alloys in many applications due to its enhanced performance. Silicon carbide $(\mathrm{SiC})$ and alumina $\left(\mathrm{Al}_{2} \mathrm{O}_{3}\right)$ are extensively used as particulate reinforcements to prepare AMCs over three decades since the advent of AMCs. The development of various production methods made it possible to incorporate several potential ceramic particles such as fly ash [4], $\mathrm{SiO}_{2}$ [5], $\mathrm{TiO}_{2}$ [6], AlN [7], $\mathrm{Si}_{3} \mathrm{~N}_{4}$ [8], $\mathrm{TiC}$ [9], $\mathrm{B}_{4} \mathrm{C}$ [10], $\mathrm{TiB}_{2}$ [11] and $\mathrm{ZrB}_{2}$ [12] to prepare AMCs.

Development and optimization of production meth- ods will improve the properties of AMCs and fulfill the requirement of various industries. Therefore, the production of AMCs with proper distribution and bonding of ceramic particles has been a challenge. AMCs are presently prepared using several methods which can be categorized into two major divisions. They are solid state processing and liquid state processing. The latter is preferred due to its simplicity, lower cost, near net shape and suitability for mass production [13].

Stir casting is the widely adopted liquid state processing method to produce AMCs [14]. The matrix material is melted in a furnace in the presence of the inert gas to avoid the formation of oxides and is stirred to form a vortex. The ceramic particles are fed at a predetermined rate to the periphery of the vortex. The stirring is continued till all the particles are properly mixed. The composite melt is then poured into a mold. The solidified composite can be further subjected to heat treatment or other secondary processes for property enhancement. The limitations of stir casting are poor distribution, lack of wettability, porosity, inter-

*Corresponding author: fax: +91 04652282471; e-mail address: josephsekhar@hotmail.com 
Table 1. The chemical composition of AA6061-T6 alloy

\begin{tabular}{lcccccccccc}
\hline Element & $\mathrm{Mg}$ & $\mathrm{Si}$ & $\mathrm{Fe}$ & $\mathrm{Mn}$ & $\mathrm{Cu}$ & $\mathrm{Cr}$ & $\mathrm{Zn}$ & $\mathrm{Ni}$ & $\mathrm{Ti}$ & Aluminum \\
\hline (wt.\%) & 0.95 & 0.54 & 0.22 & 0.13 & 0.17 & 0.09 & 0.08 & 0.02 & 0.01 & Balance \\
\hline
\end{tabular}

facial reactions and moderate volume fraction [15]. Proper selection of process parameters can help to produce sound AMCs [16]. The critical parameters of this process are the temperature of the melt, stirring speed, stirring time, particle feed rate and temperature of the mold.

$\mathrm{TiC}$ is used as reinforcement to prepare AMCs because of its improved hardness, high elastic modulus, low density, good wettability with molten aluminum and low chemical reactivity [17]. The production and characterization of aluminum alloy reinforced with TiC particles using various methods were reported in the literature [18-28]. Birol [18] prepared $\mathrm{Al} / \mathrm{TiC} \mathrm{AMC}$ by the in situ reaction of $\mathrm{K}_{2} \mathrm{TiF}_{6}$ and particulate graphite to molten aluminum and examined the effect of reaction temperature on the formation of $\mathrm{TiC}$ particles. Sharma [19] produced $\mathrm{Al} / \mathrm{TiC}$ AMC by the in situ reaction of $\mathrm{K}_{2} \mathrm{TiF}_{6}$ salt and particulate graphite with molten aluminum and concluded that $\mathrm{TiC}$ is an effective grain refiner. Ji et al. [20] investigated the creep behavior of AA2618/TiC AMC prepared by the in situ reaction of $\mathrm{Ti}$ and $\mathrm{C}$ powders with molten aluminum and reported that $\mathrm{TiC}$ particles significantly improved the creep resistance of aluminum alloy AA2618. Liang et al. [21] synthesized AA2024/TiC AMC by the in situ reaction of titanium and graphite powders with molten aluminum and estimated the effect of $\mathrm{TiC}$ particles on microstructure and tensile strength of the AMC. Jerome et al. [22] developed $\mathrm{Al} / \mathrm{TiC} \mathrm{AMC}$ by salt route and observed that $\mathrm{TiC}$ particles provided an improved wear resistance at a higher temperature. Kaftelen et al. [23] used fluxes such as $\mathrm{KAlF}_{4}$ and $\mathrm{K}_{3} \mathrm{AlF}_{6}$ to prepare AA2024/TiC AMC by stir casting and compared the properties with a similar composite synthesized by powder metallurgy route. Shu et al. [24] fabricated high volume fraction $\mathrm{Al} / \mathrm{TiC} \mathrm{AMC}$ by combustion synthesis and hot press consolidation and analyzed the effect of $\mathrm{TiC}$ particles on the abrasive resistance of the AMC. Liu et al. [25] applied ultrasonic vibration to disperse the clusters present in the $\mathrm{Al} / \mathrm{TiC} \mathrm{AMC}$ synthesized by in situ method. Thangarasu et al. [26] studied the feasibility to fabricate AA1050/TiC AMC using friction stir processing. Liu et al. [27] introduced quick preheating of reaction powders and high-intensity ultrasonic vibration to the aluminum melt to produce $\mathrm{Al} / \mathrm{TiC} \mathrm{AMC}$ by casting and observed an enhanced distribution of $\mathrm{TiC}$ particles in the aluminum matrix. Gopalakrishnan and Murugan [28] evaluated the sliding wear behavior of
AA6061/TiC AMC prepared by modified stir casting method.

In this paper, an attempt is made to fabricate a composite of aluminum alloy, AA6061, reinforced with $\mathrm{TiC}$ particles by stir casting, and the results obtained from the studies on the effect of $\mathrm{TiC}$ content on the microstructure and other properties of AMC are presented.

\section{Experimental procedure}

AA6061 rods were placed in a graphite crucible and heated using an electrical furnace with a suitable coating inside the crucible to avoid contamination. The chemical composition of the AA6061 aluminum alloy is presented in Table 1. The casting facility used to fabricate AA6061/TiC AMCs is shown in Fig. 2. The temperature of the furnace was maintained at $750^{\circ} \mathrm{C}$. The mechanical stirrer was dipped into the aluminum melt after all the rods were melted completely in the presence of inert environment. Then the stirrer was rotated at a constant speed of $300 \mathrm{rpm}$ to form a vortex. Measured quantity of TiC particles at room temperature was gradually fed to the vortex at a feed rate of approximately $15 \mathrm{~g} \mathrm{~min}^{-1}$. Stirring of the melt and feeding of $\mathrm{TiC}$ particles were continued intermittently for $30 \mathrm{~min}$. The composite melt was then poured into a die preheated to $300^{\circ} \mathrm{C}$. Castings were taken with various amounts of $(0,5,10$ and $15 \mathrm{wt} . \%) \mathrm{TiC}$ particles. The SEM micrographs of the $\mathrm{TiC}$ particles given in Fig. 1 exhibit the irregular shape with an average size close to $2 \mu \mathrm{m}$.

Specimens were prepared from the castings, and they were polished using standard metallographic technique and etched with Keller's reagent. The etched specimens were observed using an optical microscope and a scanning electron microscope (SEM). X-ray diffraction patterns (XRD) were recorded using Panalytical X-ray diffractometer. The microhardness was measured using a microhardness tester at $5 \mathrm{~N}$ load applied for $15 \mathrm{~s}$. The tensile specimens were prepared as per ASTM E8M standard having a gauge length, width and thickness of 40,7 and $6 \mathrm{~mm}$, respectively. The ultimate tensile strength (UTS) was estimated using a computerized universal testing machine. The fracture surfaces of the failed tensile specimens were also observed using SEM.

The sliding wear behavior of AA6061/TiC AMCs was measured using a pin-on-disc wear apparatus 

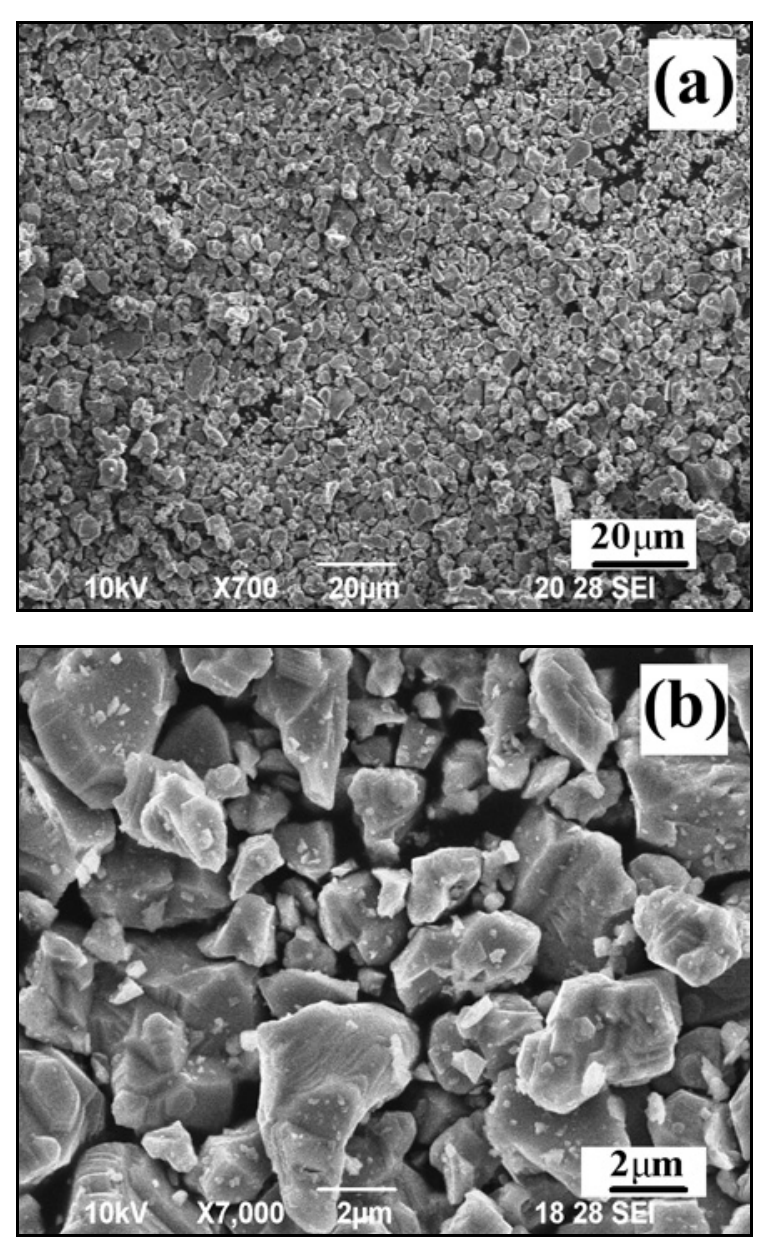

Fig. 1. SEM micrographs of TiC particles (a), (b).

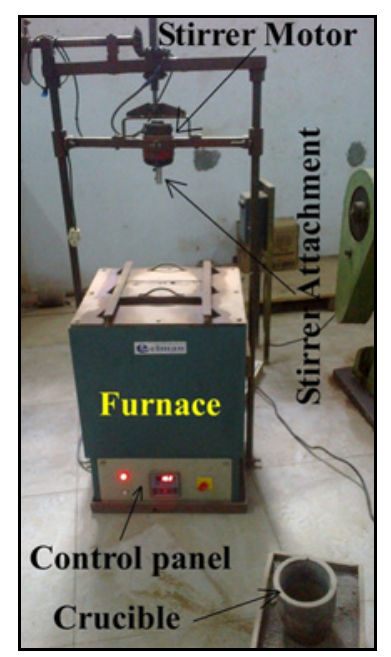

Fig. 2. Stir casting facility.

(DUCOM TR20-LE) at the room temperature according to ASTM G99-04 standard. Specimens of size $6 \mathrm{~mm} \times 6 \mathrm{~mm} \times 60 \mathrm{~mm}$ were prepared from the

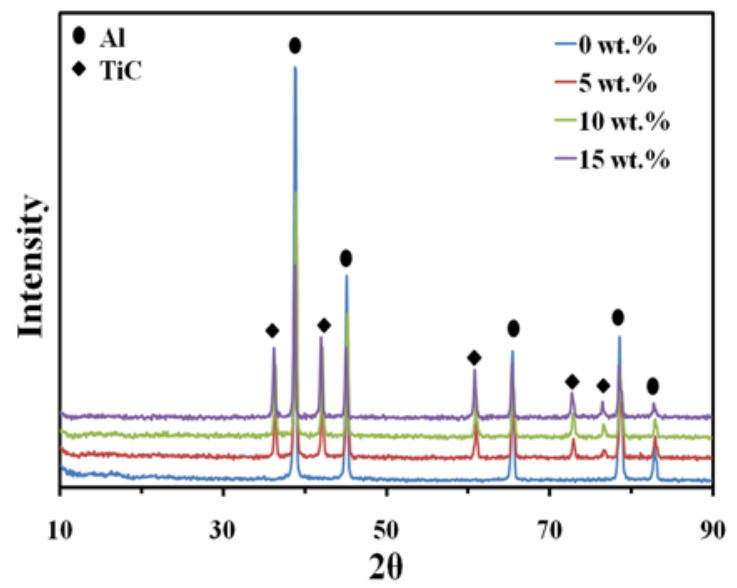

Fig. 3. XRD patterns of AA6061/TiC stir cast composites.

castings. The wear test was conducted at a normal force of $25 \mathrm{~N}$, sliding velocity and distance of $1 \mathrm{~m} \mathrm{~s}^{-1}$ and $2500 \mathrm{~m}$, respectively. The polished surface of the pin was slid on a hardened chromium steel disc. A computer-aided data acquisition system was used to monitor the loss of height. The volumetric loss was computed by multiplying the cross-sectional area of the test pin with its loss of height. The wear rate was obtained by dividing volumetric loss to sliding distance. The worn surfaces of the test specimens were observed using SEM. The wear debris which was scattered on the face of the counterface was carefully collected and characterized using SEM.

\section{Results and discussion}

\subsection{X-ray diffraction analysis of A A6061/TiC AMCs}

Aluminum alloy AA6061 reinforced with TiC particulate composites was successfully produced by stir casting method. The XRD patterns of the prepared AA6061/TiC AMCs are presented in Fig. 3. The diffraction peaks of $\mathrm{TiC}$ particles are visible, and the intensity of the $\mathrm{TiC}$ peaks increases as $\mathrm{TiC}$ content is increased. The XRD patterns confirm the reinforcement of $\mathrm{TiC}$ particles in the aluminum alloy and a slight shift of aluminum peaks due to the reinforcement of $\mathrm{TiC}$ particles is observed in the composites. It is also evident from the XRD pattern that no other elements except $\mathrm{Al}$ and $\mathrm{TiC}$ are present. This indicates that $\mathrm{TiC}$ particles preserve their integrity during the casting process, and did not react with molten aluminum to produce any other compounds such as $\mathrm{Al}_{3} \mathrm{Ti}$ or $\mathrm{Al}_{3} \mathrm{C}_{4}$, and $\mathrm{TiC}$ particles behave thermodynamically stable at the selected casting parameters. Stir casting is prone to the reaction between the rein- 
forcement and the molten matrix. Lee et al. [29] exclusively reported the possible reaction products from $\mathrm{Al} / \mathrm{TiC} \mathrm{AMCs}$ by liquid metallurgy route and concluded that the reaction products tend to accumulate on the particle-matrix interface, and deteriorate the mechanical and tribological properties. The peaks observed in XRD test could reveal the availability of unwanted compounds in the AMC. A clean interface between aluminum alloy and $\mathrm{TiC}$ particles observed in this test proves that there is no other compound present in this composite. Lower casting temperature can be attributed to one of the reasons for this structure.

\subsection{Microstructure of AA6061/TiC AMCs}

The optical and SEM micrographs of as-cast AA6061 are shown in Fig. 4. It depicts the formation of a typical dendritic structure of aluminum, which results from the high rate of cooling during the solidification of the casting. The dendritic structure exhibits elongated primary $\alpha$-Al dendritic arms having a high aspect ratio. The secondary precipitation phase $\mathrm{Mg}_{2} \mathrm{Si}$ is observed along the dendritic boundaries due to the high solubility limits of the alloying elements such as $\mathrm{Mg}$ and $\mathrm{Si}$.

$\mathrm{TiC}$ particles are known for its grain refining action [28] and grain refinement during solidification. The complete disappearance of dendritic structure in the matrix and the refined dendritic structure into a grainy structure are observed in the SEM micrographs of the fabricated AA6061/TiC AMCs as shown in Fig. 5. The factors such as the better distribution of $\mathrm{TiC}$ particles and increase in a number of grain nucleation sites during solidification could be the cause of this grain refinement. The more the content of $\mathrm{TiC}$ particles the more will be the resistance to grain growth and a number of nucleation sites. As a result, the formation of finer grains takes place due to enhanced grain refinement.

The distribution of reinforcement particles in the matrix material takes place in three stages as far as stir casting is concerned: (a) distribution of particles in the melt as a result of mixing, (b) distribution of particles in the melt before pouring or solidification and (c) redistribution of particles as a result of solidification [14]. It is evident from Fig. 5 that TiC particles are distributed throughout the aluminum matrix and the distribution is fairly homogeneous in many places. Closely located $\mathrm{TiC}$ particle clusters are also seen in some places. The mechanical stirring action drives the particles to be dispersed effectively in the melt. Suspension of $\mathrm{TiC}$ particles in the melt throughout the stirring period before pouring is needed to achieve proper distribution. It is reported that if the density variation between the matrix and ceramic particle is more than $2 \mathrm{~g} \mathrm{~cm}^{-3}$, the sinking rate of particles size is
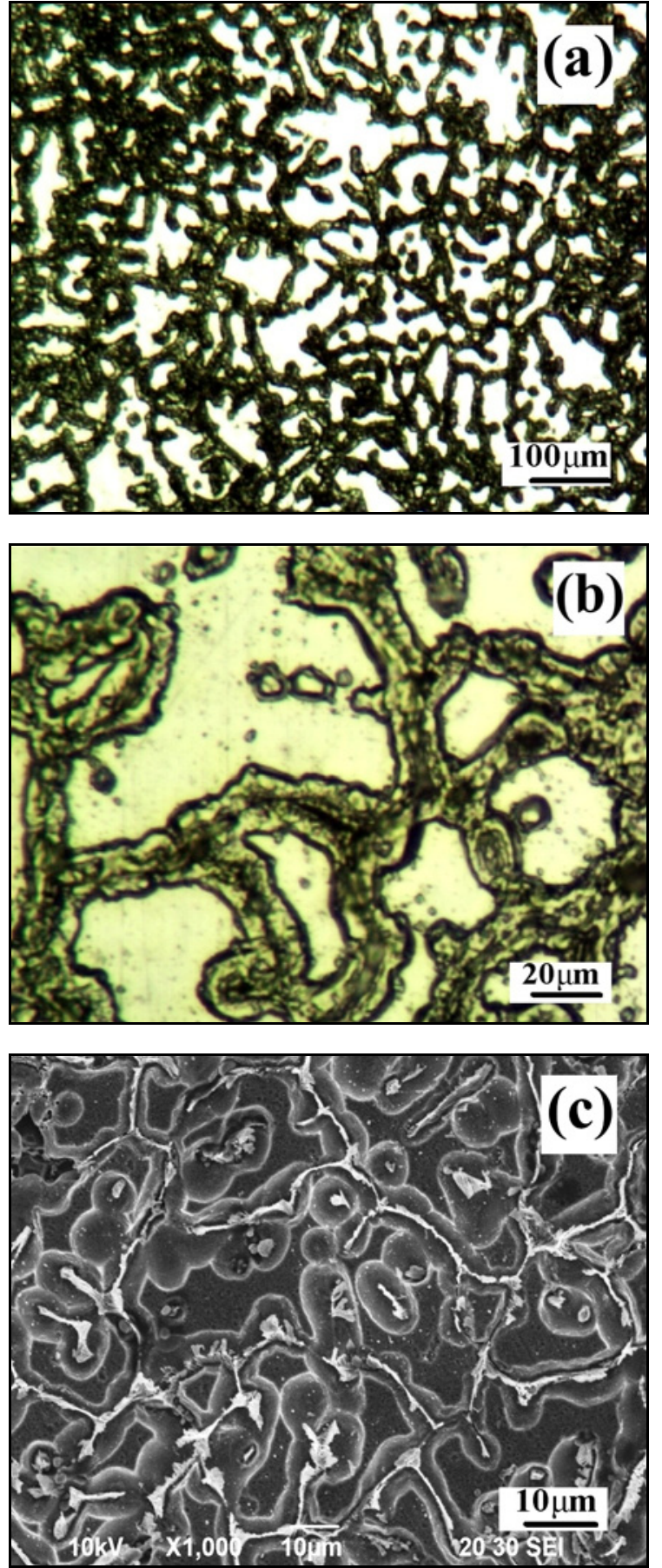

Fig. 4. Optical (a), (b) and SEM (c) micrographs of cast matrix alloy AA6061.

less than $10^{-4} \mathrm{~cm} \mathrm{~min}^{-1}$ [30]. The average size of $\mathrm{TiC}$ particles in the present work is about $2 \mu \mathrm{m}$. The density variation between the aluminum matrix and $\mathrm{TiC}$ particles is nearly $2 \mathrm{~g} \mathrm{~cm}^{-3}$. Therefore, the particles can suspend in the melt for a longer time. The wetting action between $\mathrm{TiC}$ particles and the aluminum melt will offer resistance to the free movement of $\mathrm{TiC}$ particle within the melt. The incorporation of $\mathrm{TiC}$ particles 

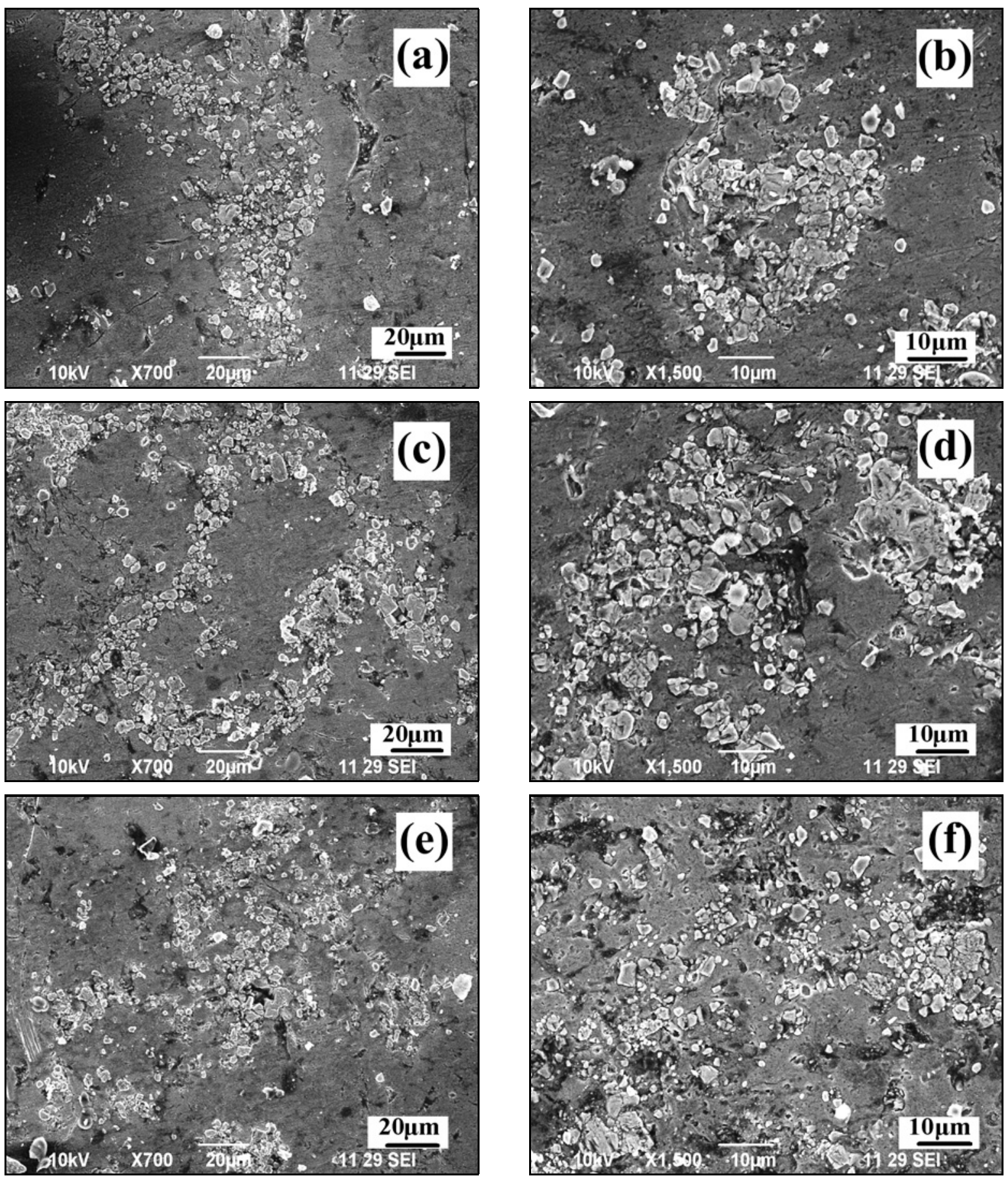

Fig. 5. SEM micrographs of AA6061/TiC stir cast composites at lower magnification.

into the aluminum melt increases the viscosity of the melt and leads to retard the free movement of $\mathrm{TiC}$ particle within the melt. The more the content of $\mathrm{TiC}$ particle, the more will be the viscosity and resistance to the movement of particles.

The solidification pattern plays a major role in the redistribution of particles after pouring. During solidification, several factors such as convection current, movement of the solidification front against particles and buoyant motion of particles influence the distri- bution of particles in AMCs [31]. If the solidification front pushes the particles, the distribution will be intergranular. Otherwise, the intragranular distribution will occur if the solidification front engulfs the particles. Intragranular distribution of ceramic particles is preferable compared to intergranular distribution to attain higher mechanical and tribological properties. Figures $5 \mathrm{a}$ and $5 \mathrm{c}$ show the location of most of the TiC particles in intergranular regions when the content of $\mathrm{TiC}$ is up to $10 \mathrm{wt} . \%$. Intragranular distribution of 


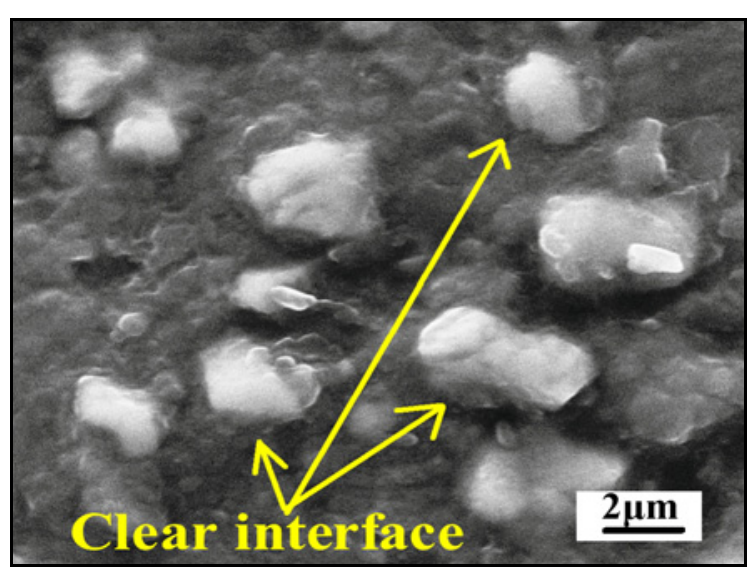

Fig. 6. SEM micrographs of AA6061/15 wt.\% TiC stir cast composite at higher magnification.

TiC particles is observed at 15 wt. $\%$.

Some investigators $[17,32,33]$ observed reaction products at the interface. The SEM micrograph of AA6061/15 wt.\% TiC AMC at higher magnification given in Fig. 6 shows a clear interface existing between the aluminum matrix and $\mathrm{TiC}$ particle without the presence of any reaction products. The formation of any undesirable compounds due to the interfacial reaction was not observed in the tested composite. This proves that the process parameters are selected appropriately. $\mathrm{TiC}$ particles are thermodynamically stable under the experimental conditions since it did not decompose during casting. Further, it is evident from Fig. 6 that there are no pores or voids around the $\mathrm{TiC}$ particles, and they are properly bonded to the matrix alloy.

\subsection{Mechanical properties of AA6061/TiC $A M C s$}

The effect of $\mathrm{TiC}$ particles on the mechanical properties of AA6061/TiC AMC for different weight percentages is shown in Fig. 7. AA6061/15 wt.\% TiC AMC exhibits $134.4 \%$ higher microhardness and $70.5 \%$ higher UTS compared to the unreinforced AA6061 alloy. This is because of the dissimilar thermal expansion coefficient of AA6061 and TiC particles. Strain fields are created around $\mathrm{TiC}$ particles during solidification of the composite. The strain fields pile up dislocations and the propagation of cracks during tensile loading encounter resistance due to the interaction between dislocations and $\mathrm{TiC}$ particles. The detachment of $\mathrm{TiC}$ particles is delayed due to the presence of a clear interface and proper bonding. The dispersion of $\mathrm{TiC}$ particles all over the aluminum matrix provides Orowan strengthening [34]. Therefore, microhardness and UTS are improved. A number of strain fields are proportional to the weight percentage of $\mathrm{TiC}$ particles. Hence, more strain fields are created as the weight
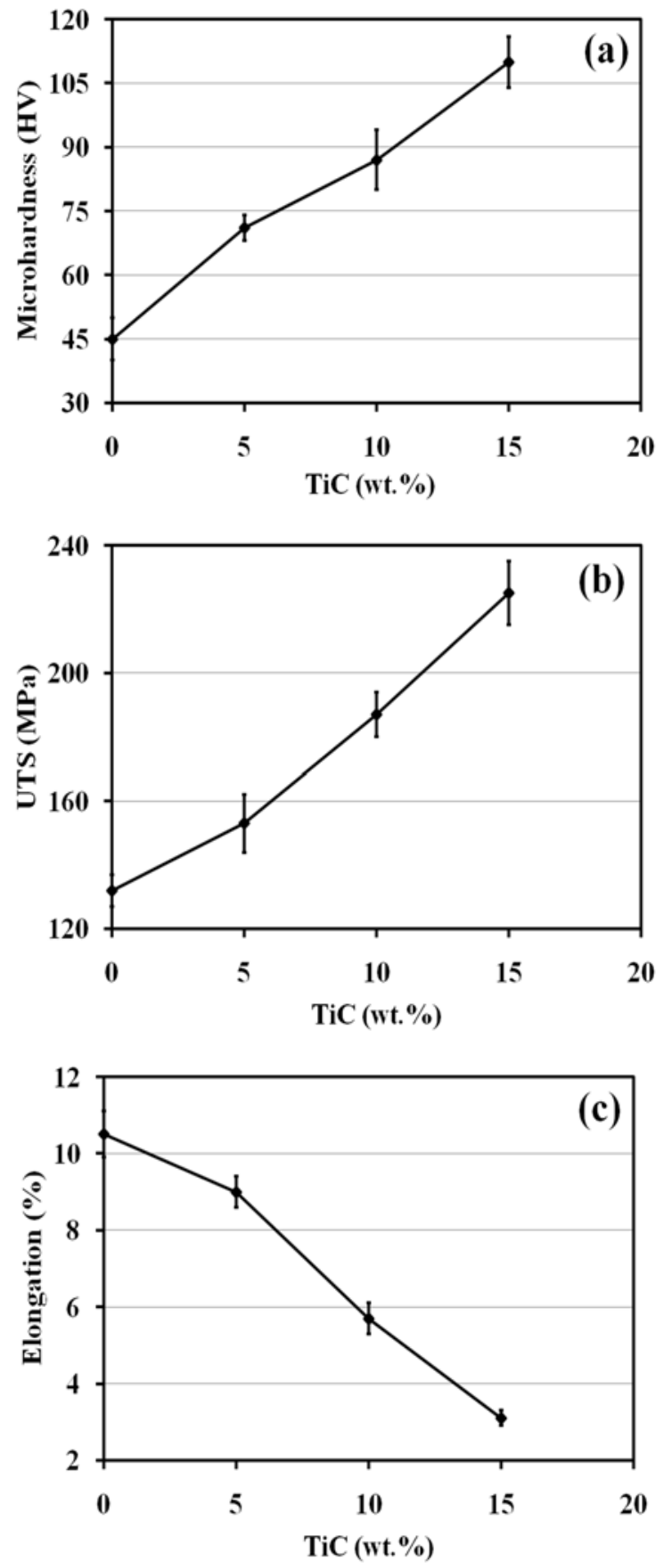

Fig. 7. Effect of TiC content on: microhardness (a), UTS (b) and elongation of $\mathrm{AA} 6061 / \mathrm{TiC}$ stir cast composites (c).

percentage of $\mathrm{TiC}$ particles is increased. The elongation of the AMCs decreases as shown in Fig. 7c when the weight percentage of $\mathrm{TiC}$ particles is increased. Similar results were reported by Shu et al. [24]. The grain refinement and reduction of ductile matrix content, when the weight percentage of $\mathrm{TiC}$ particles is increased, reduce the ductility of the AMCs.

The fracture morphology of the tensile test spec- 

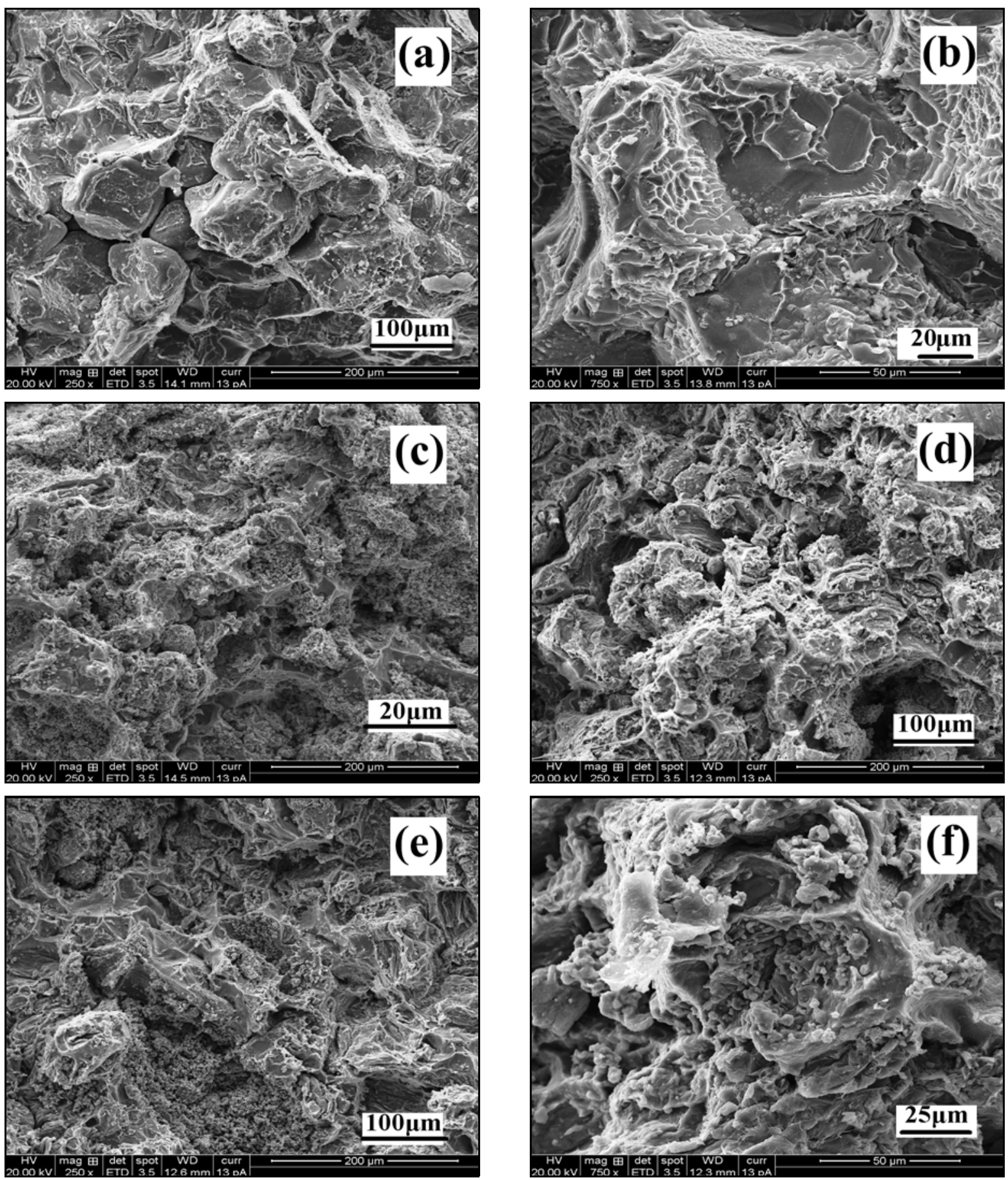

Fig. 8. Fracture morphology of AA6061/TiC stir cast composites containing TiC: 0 wt.\% (a), 0 wt.\% (b), 5 wt.\% (c), 10 wt.\% (d), 15 wt.\% (e), and 15 wt.\% (f).

imens of AA6061/TiC AMCs is presented in Fig. 8. Figures $8 \mathrm{a}$ and $8 \mathrm{~b}$ show the homogeneously distributed large size voids which indicate a ductile fracture. Figures $8 \mathrm{c}-\mathrm{e}$ show smaller size voids compared to that of the matrix alloy which indicates macroscopically brittle fracture and microscopically ductile fracture. The reinforcement of $\mathrm{TiC}$ particles to the matrix alloy refined the grain size and reduced the ductility which resulted in smaller voids. The magnified fracture morphology of AA6061/15 wt.\% $\mathrm{TiC}$ AMC given in Fig. 8f shows that $\mathrm{TiC}$ particles remain intact in several places which gives evidence for the existence of good bonding between the aluminum matrix and the reinforced $\mathrm{TiC}$ particles. 


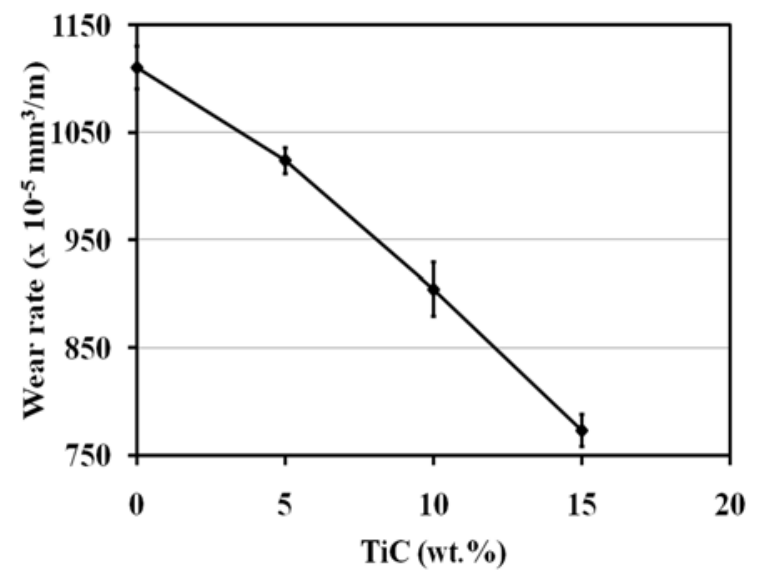

Fig. 9. Effect of $\mathrm{TiC}$ content on the wear rate of AA6061/TiC stir cast composites.

\subsection{Sliding wear behavior of AA6061/TiC AMCs}

The effect of weight percentage of $\mathrm{TiC}$ particles on the wear rate of $\mathrm{AA} 6061 / \mathrm{TiC} \mathrm{AMCs}$ is depicted in
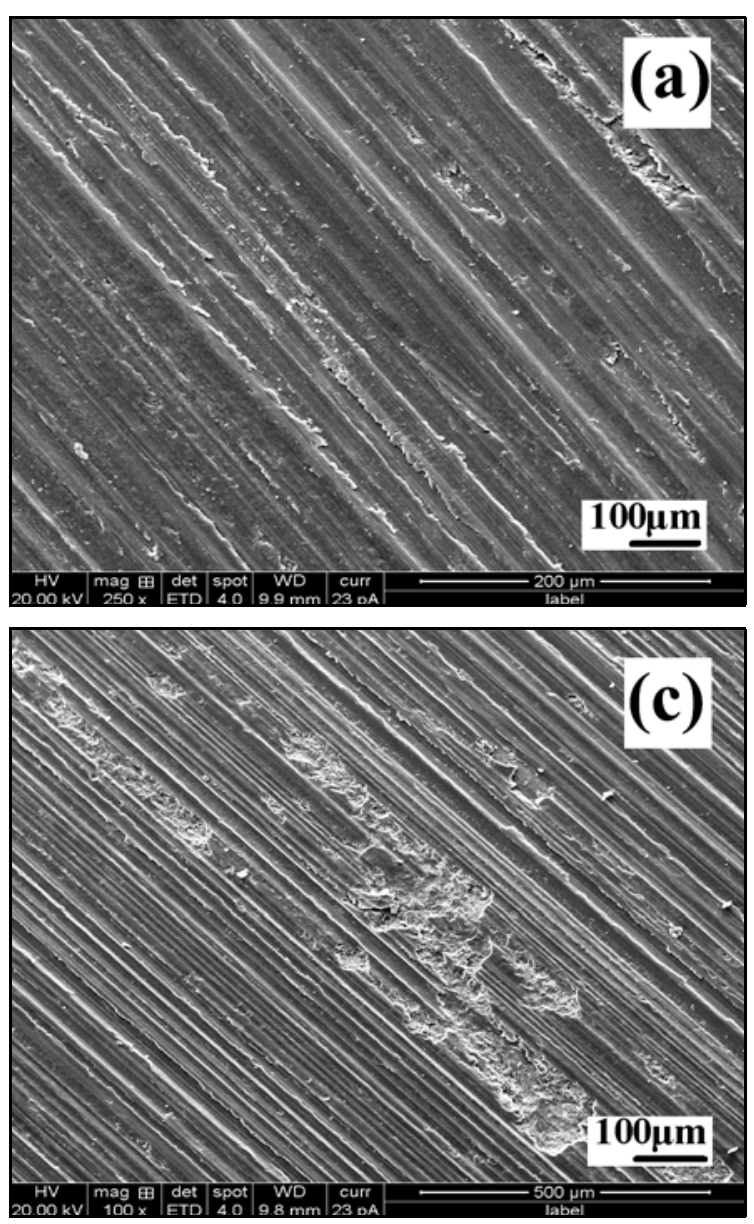

Fig. 9. It is evident from Fig. 9 that the TiC particles reduce the wear rate considerably. AA6061/15 wt.\% TiC AMC exhibits $30.5 \%$ lower wear rate compared to unreinforced AA6061. This is attributed to the high strength and hardness of composites with TiC. The relationship between material hardness and material removal during sliding is described as [35]:

$$
\begin{aligned}
& \text { Volume loss }= \\
& \text { Wear coefficient } \times \text { Applied load } \times \text { Sliding distance }
\end{aligned}
$$

Equation (1) shows that the higher the hardness of the material, the lower will be the wear rate. The enhanced hardness of the composite offers resistance to the cutting action of the counter surface during sliding. A good interfacial bonding between the TiC particles and the aluminum matrix retards the removal of particles during sliding. When the weight percentage of $\mathrm{TiC}$ particles increases, the contribution of above factors further increases. As a result, the wear rate is further reduced.
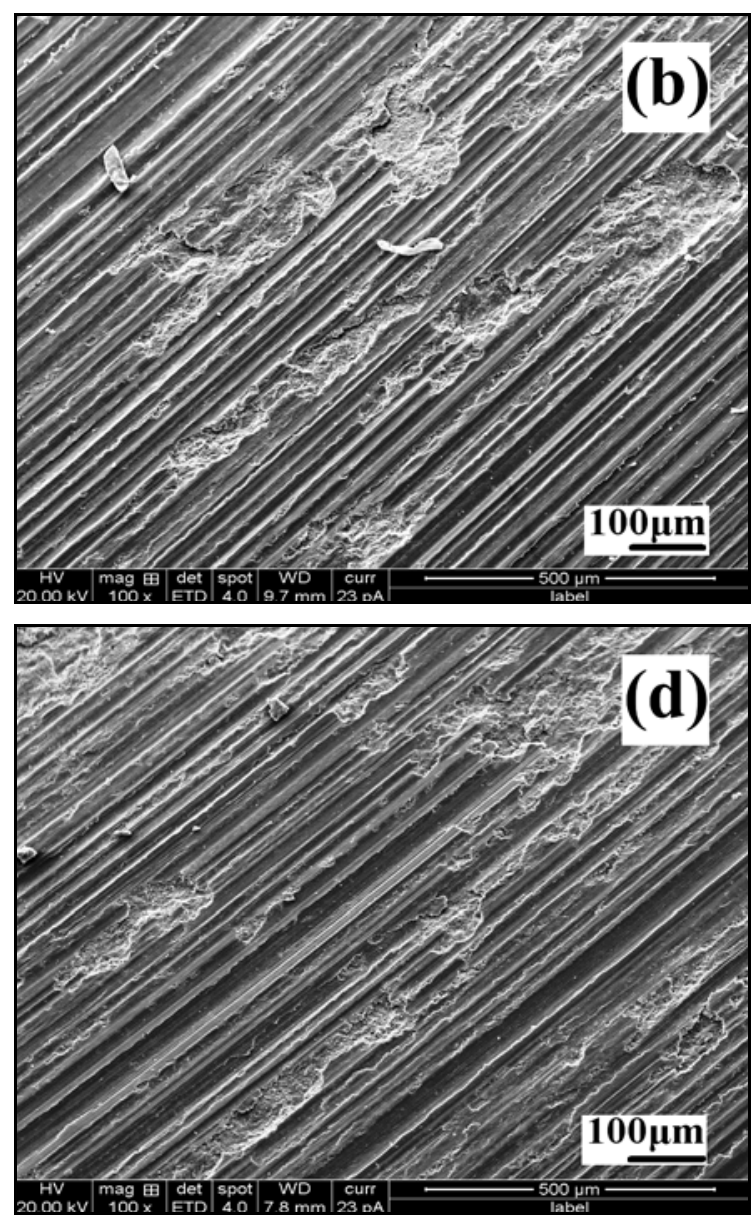

Fig. 10. Worn surface of AA6061/TiC stir cast composites containing TiC: 0 wt.\% (a), 5 wt.\% (b), 10 wt.\% (c), and 15 wt. \% (d). 

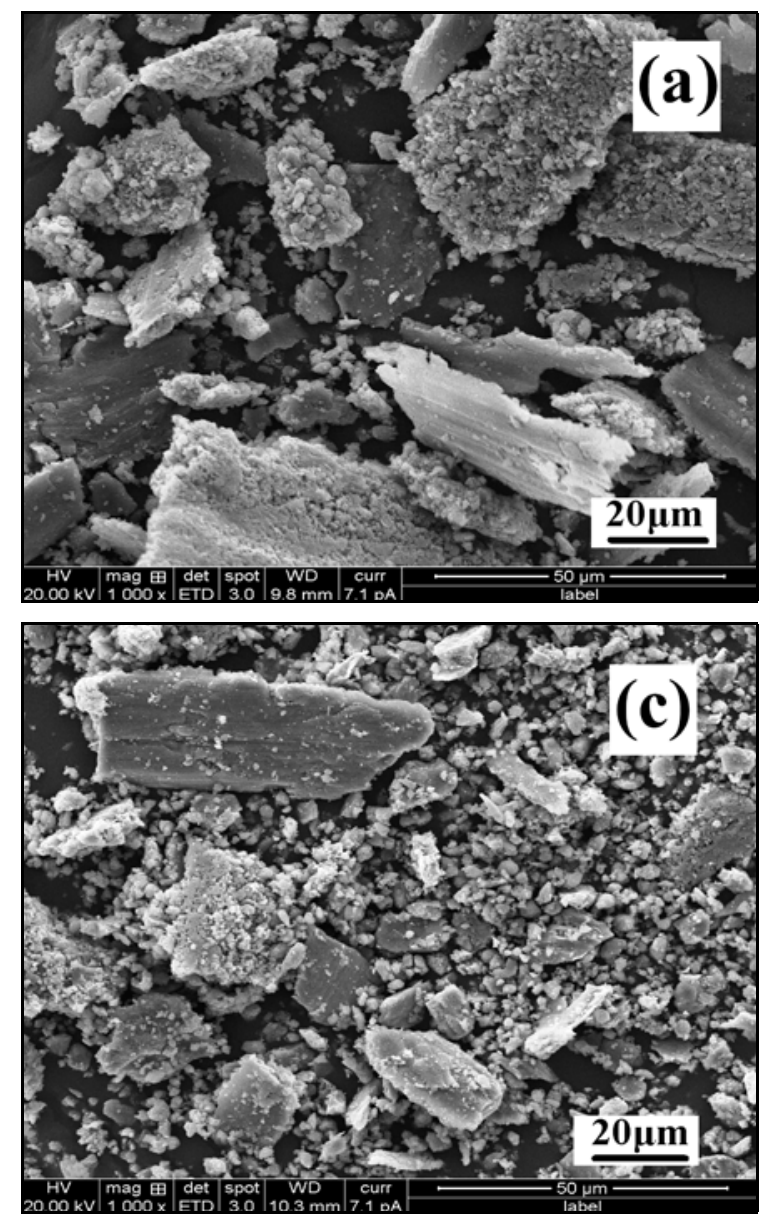
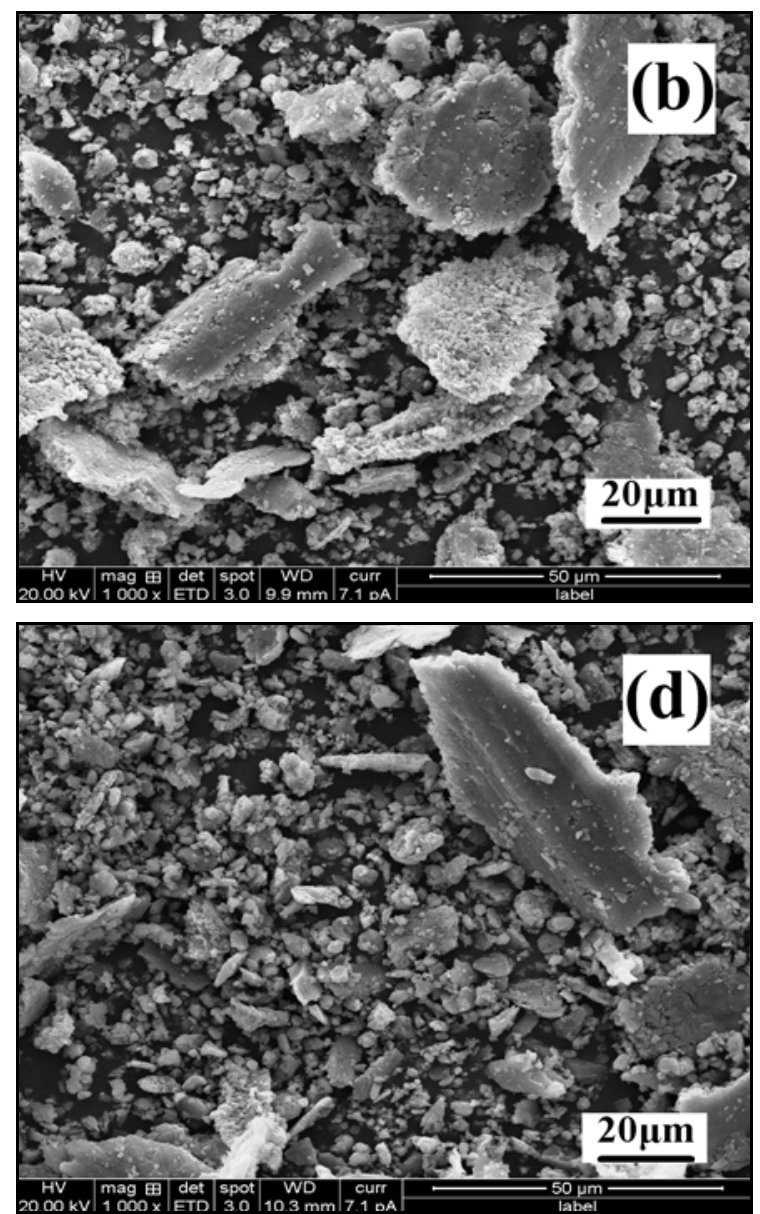

Fig. 11. Wear debris of AA6061/TiC stir cast composites containing TiC: 0 wt.\% (a), 5 wt.\% (b), 10 wt.\% (c), and 15 wt.\% (d).

The effect of weight percentage of $\mathrm{TiC}$ particles on the morphology of the worn surface of AA6061/TiC AMCs is shown in Fig. 10. The worn surface of the matrix alloy in Fig. 10a shows a large number of parallel grooves. But the grooves are blended at the edges due to piled up plasticized matrix. The frictional heat due to sliding between matrix alloy and counter surface causes plastic deformation. The wear mode is observed to be adhesive. The worn surfaces of AA6061/TiC AMCs (Figs. 10b-d) show distinct parallel grooves which bear evidence to abrasive wear mode. The edges of the grooves are sharper due to the ploughing action of the counter surface. Loose wear debris is also seen on the worn surface. As the weight percentage of $\mathrm{TiC}$ particles increases, the number and size of pits on the worn surface decreases.

The effect of weight percentage of $\mathrm{TiC}$ particles on the morphology of wear debris of AA6061/TiC AMCs is shown in Fig. 11. It reveals that the increase in weight percentage of $\mathrm{TiC}$ particle results in finer wear debris. The wear debris of the matrix alloy in Fig. 11a exhibits large thin plate-like morphology, which is due to adhesive wear between matrix and counter surface. Local welding or adhesion takes place between the plasticized asperities of matrix and counter surface. As sliding continues, the local adhesion spreads and it is removed in the form of thin plates. When $\mathrm{TiC}$ particles are added to the matrix alloy, the local adhesion is prevented and the wear mode shifts from adhesive to abrasive. During the initial stages of sliding of AA6061/5 wt.\% TiC AMC, some of TiC particles are removed due to cutting action of counter surface. When the matrix surrounding the TiC particle is removed, $\mathrm{TiC}$ particle is eventually pulled out. These $\mathrm{TiC}$ particles are trapped between the specimen and the counter surface, converting two-body abrasion into three-body abrasion. Rolling is promoted to over sliding which reduces the wear rate. The three-body abrasion generates finer wear debris. Figures 11c and $11 \mathrm{~d}$ show that the weight percentage of $\mathrm{TiC}$ increases the milling action. As a result, it increases the forms of finer spherical debris.

\section{Conclusions}

In the present work, AA6061/TiC AMCs were successfully fabricated using stir casting. The effect of 
TiC content on microstructure, mechanical properties, and wear rate was analyzed, and the results are summarized as follows:

- The XRD pattern of the composite showed the peaks of $\mathrm{TiC}$ particles clearly without the presence of any other peaks. The thermodynamic stability of $\mathrm{TiC}$ for the selected casting parameters was also confirmed from the XRD pattern.

- The distribution of $\mathrm{TiC}$ in the aluminum matrix was fairly homogeneous. Some clusters of TiC particle were seen. The distribution of $\mathrm{TiC}$ particles was intragranular at 15 wt.\% while the distribution was intergranular at 5 and 10 wt. $\%$.

- TiC particles refined the grains of matrix alloy and improved the bonding of the matrix. A clear interface between the $\mathrm{TiC}$ particle and the aluminum matrix was obtained without the presence of reaction products, pores, and voids.

- TiC particles enhanced the microhardness and UTS of the composite but reduced the ductility of the composite. AA6061/15 wt.\% TiC AMC exhibited $134.4 \%$ higher microhardness and $70.5 \%$ higher UTS compared to unreinforced AA6061 alloy, whereas the increase in $\mathrm{TiC}$ content shifted the fracture mode from ductile to brittle.

- TiC particles enhanced the wear resistance of the composite but reduced the ductility of the composite. AA6061/15 wt.\% TiC AMC exhibited 30.5\% lower wear rate when compared with unreinforced AA6061 alloy.

- The increase in $\mathrm{TiC}$ content shifted the wear mode from adhesive to abrasive. The size of wear debris became finer when the content of $\mathrm{TiC}$ particles was increased due to three-body abrasion.

\section{References}

[1] Raaft, M., Mahmoud, T. S., Zakaria, H. M., Khalifa, T. A.: Mater. Sci. Eng. A, 528, 2011, p. 5741. doi:10.1016/j.msea.2011.03.097

[2] Kumar, S., Pandey, R., Panwar, R. S., Pandey, O. P.: J. Mater. Perform., 22, 2013, p. 3550. doi:10.1007/s11665-013-0642-8

[3] Lu, D., Celis, J. P., Kenzaric, S., Fournée, V., Zhou, D. B.: Wear, 270, 2011, p. 528 doi:10.1016/j.wear.2011.01.007

[4] Selvan, J. D. R., Smart, D. S. R., Dinaharan, I.: Mater. Des., 49, 2013, p. 28. doi:10.1016/j.matdes.2013.01.053

[5] Hemanth, J.: Compos. Part B, 42, 2011, p. 1826. doi:10.1016/j.compositesb.2011.06.022

[6] Sivasanraran, S., Sivaprasad, K., Narayanasamy, R., Iyer, V. K.: Powder Technol., 201, 2010, p. 70. doi:10.1016/j.powtec.2010.03.013

[7] Liu, Z. Y., Kent, D., Schaffer, G. B.: Mater. Sci. Eng. A, 513-514, 2009, p. 352. doi:10.1016/j.msea.2009.02.001

[8] Moghaddas, M. A., Bozorg, S. F. K.: Mater. Sci. Eng. A, 559, 2013, p. 187. doi:10.1016/j.msea.2012.08.073
[9] Quainlin, W. U., Ang, C., Xue, F., Sun, Y.: Mater. Des., 32, 2011, p. 4999 doi:10.1016/i.matdes.2011.06.045

[10] Mindivan, H.: Mater. Lett., 64, 2010, p. 405. doi:10.1016/j.matlet.2009.11.032

[11] Niranjan, K., Lakshminarayanan, P. R.: Mater. Des., 47, 2013, p. 167. doi:10.1016/j.matdes.2012.11.035

[12] Dinaharan, I., Murgan, N.: Trans. Nonferrous Met. Soc. China, 22, 2012, p. 810. doi:10.1016/S1003-6326(11)61249-1

[13] Taha, M. A.: Mater. Des., 22, 2001, p. 431. doi:10.1016/S0261-3069(00)00077-7

[14] Hashim, J., Looney, L., Hashimi, M. S. J.: J. Mater. Process. Technol., 92-93, 1999, p. 1. doi:10.1016/S0924-0136(99)00118-1

[15] Lloyd, D. J.: Int. Mater. Rev., 39, 1994, p. 1. doi:10.1179/imr.1994.39.1.1

[16] Prabu, B. S., Karunamoorthy, L., Katheresan, S., Mohan, B.: J. Mater. Process. Technol., 171, 2006, p. 268. doi:10.1016/i.jmatprotec.2005.06.071

[17] Kerti, I.: Mater. Lett., 593, 2005, p. 795. doi:10.1016/j.matlet.2005.06.032

[18] Birol, Y.: J. Alloy Compd., 454, 2008, p. 110. doi:10.1016/j.jallcom.2006.12.016

[19] Sharma, A.: Int. J. Cast Met. Res., 21, 2008, p. 226. doi:10.1179/136404608X361990

[20] Ji, F., Ma, M. Z., Song, A. J., Zhang, W. G., Zong, H. T., Liang, S. X., Osamu, Y., Liu, R. P.: Mater. Sci. Eng. A, 506, 2009, p. 58. doi:10.1016/j.msea.2008.11.010

[21] Liang, Y. F., Zhou, J. E., Dong, S. Q.: Mater. Sci. Eng. A, 527, 2010, p. 7955. doi:10.1016/j.msea.2010.08.098

[22] Jerome, S., Ravisankar, B., Mahato, P. B., Natarajan, S.: Tribol. Int., 43, 2010, p. 2029. doi:10.1016/i.triboint.2010.05.007

[23] Kaftelen, H., Unlü, N., Göller, G., Öveçoglu, M. L., Henein, H.: Compos., Part B, 42, 2011, p. 812. doi:10.1016/j.compositesa.2011.03.016

[24] Shu, S., Lu, J., Qiu, F., Xuan, Q., Jiang, Q.: Mater. Sci. Eng. A, 528, 2011, p. 1931. doi:10.1016/j.msea.2010.11.052

[25] Liu, Z. W., Rakita, M., Han, Q., Li, J. G.: Mater. Res. Bull., 46, 2011, p. 1674. doi:10.1016/i.materresbull.2011.06.003

[26] Thangarasu, A., Murugan, N., Dinaharan, I., Vijay, S. J.: Sadhana, 37, 2012, p. 579. doi:10.1007/s12046-012-0097-x

[27] Liu, Z., Han, Q., Li, J.: Compos., Part B, 43, 2012, p. 2429. doi:10.1016/j.compositesb.2011.11.004

[28] Gopalakrishnan, S., Murugan, N.: Compos., Part B, 43, 2012, p. 302. doi:10.1016/i.compositesb.2011.08.049

[29] Lee, K. B., Sim, H. S., Kwon, H.: Metall. Mater. Trans. A, 36, 2005, p. 2517. doi:10.1007/s11661-005-0125-0

[30] Han, Y., Liu, X., Bian, X.: Compos., Part A, 33, 2002, p. 439. doi:10.1016/S1359-835X(01)00124-5

[31] Bauri, R., Yadav, D., Suhas, G.: Mater. Sci. Eng. A, 528, 2011, p. 4732. doi:10.1016/j.msea.2011.02.085

[32] Lashgari, H. R., Sufizadeh, A. R., Emamy, M.: Mater. Des., 31, 2010, p. 2187. doi:10.1016/j.matdes.2009.10.049 
[33] Rajan, T. P. D., Pillai, R. M., Pai, B. C., Satyanarayana, K. G., Rohatgi, P. K.: Compos. Sci. Technol., 15-16, 2007, p. 3369.

doi:10.1016/i.compscitech.2007.03.028

[34] Zhang, Z., Chen, D. L.: Mater. Sci. Eng. A, 483-484, 2008, p. 148. doi:10.1016/j.msea.2006.10.184
[35] Kumar, S., Sarma, V. S., Murty, B. S.: Mater. Sci. Eng. A, 465, 2007, p. 160. doi:10.1016/i.msea.2007.02.117 